\title{
THE DETERMINANTS OF CAR OWNERSHIP AMONG WORKING ADULTS IN PENANG, MALAYSIA
}

\author{
LIAN YEE LEE \\ School of Social \\ Universiti Sains Malaysia \\ YONG KANG CHEAH \\ College of Business \\ Universiti Malaysia
}

\begin{abstract}
Penang has the third highest rate of car ownership in Malaysia. Traffic congestion issues have worsened alarmingly over the past few years. The objective of the present study was to investigate the factors affecting car ownership in Penang. A logit model and data from a primary survey consisting of 498 respondents were used for an in-depth analysis. The findings of the present study show that age, gender, ethnicity, income, education and parking issues are significant determinants of car ownership. In particular, individuals who are aged between 26 and 35 years; females; Chinese; high income earners and tertiary-educated, are more likely to own cars compared to others. Based on these findings, several intervention strategies are recommended.
\end{abstract}

Keywords: Car; congestion; ownership; traffic; transportation.

JEL classification code: D00; D10; R41

\section{Introduction}

A car is defined as a durable good which generates utilities to consumers. In today's society, a car plays an important role in connecting people to the job market, and it cannot be denied that car ownership has become a norm in the society. Car ownership also symbolises one's status, as it represents an individual's achievement, wealth and prestige (Golob and Hensher, 1998).

In Penang, the demand for cars has been increasing over the last few decades. The Free Trade Zone in Bayan Lepas area has attracted lots of foreign investors with number of more than 200 multinational corporations thus creating lots of job opportunities in the market. This, in turn, has attracted immigrants from elsewhere, thus resulting in an increase in car ownership. The Star (2011) reported that there were approximately 2.21 million registered vehicles in Penang in the year 2010. In spite of its limited land capacity, Penang had the third highest number of newly-registered vehicles in Malaysia (110,882 vehicles), which ranked after the Federal Territory of Kuala Lumpur (306,513 vehicles) and Johor (145,040 vehicles) (The Star, 2011).

The increase in car ownership has become a serious issue worldwide, most notably, in in Singapore, Hong Kong, Canada, the United Kingdom (UK) and the United States (US). All these countries face an identical problem, that is, traffic congestion. Hence, numerous tough intervention strategies such as quota, road and import tax, and improvement in public transport have been implemented in their efforts to reduce car ownership. Nowadays, Penang citizens face serious traffic congestion problems because of the increase in the number of cars in the state. Heavy traffic congestion usually occurs in the morning and in the evening, especially during peak hours. 
It appears, therefore, an effort to overcome the traffic congestion problems in Penang, an in-depth investigation of the factors affecting car ownership is vital. Rahim and Hamsa (2013) and Loo et al. (2015) are notable in examining the use of vehicles in Malaysia. However, their scopes are limited to the population in a selected university and the city. The determining factors of the likelihood of using and owning cars are also not explained in detail. The research question that remains unanswered and unaddressed is what are the factors that influence car ownership in Penang? A better understanding of how socio-demographic factors such as age, gender, income, ethnicity and education can affect car ownership is important to policy makers to design proper intervention measures.

\section{Theoretical Basis}

As an economic perspective, individuals tend to behave rationally in order to maximise the benefits received from consuming market goods and services, while minimising the incurred costs (Frank, 2008). Hence, rational individuals will take into account of the costs and benefits of owning a car, and will own a car only when the benefits received are higher than the incurred costs.

The costs and benefits of owning a car comprise of both monetary and non-monetary values. Generally, the costs of owning a car are the price of the car, road tax, maintenance costs, traffic congestion and environmental pollution, whereas the benefits are comfort and convenience. Rational individuals will tend to maximise the total net benefits received from owning a car by equalising the marginal costs (MCs) and marginal benefits (MBs). MC refers to an additional cost borne by individuals when owning a car, while MB refers to an additional benefit received by individuals when owning a car.

Since car ownership involves costs, MC increases with every additional unit of car owned. MB, on the other hand, decreases with every additional unit of car owned because of the law of diminishing return. Based on the costbenefit marginal analysis, it can be concluded that rational individuals prefer to own a cars only if the MB is greater than the MC. Simply putting, the marginal cost-benefit approach to the decisions can be expressed as follows (Frank, 2008):

$$
\begin{aligned}
& \mathrm{MB}>\mathrm{MC} \text {; own a car } \\
& \mathrm{MB}<\mathrm{MC} \text {; do not own a car }
\end{aligned}
$$

\section{Review of Past Literature}

The relationship between age and car ownership was inconclusive. Raphael and Rice (2002) used a survey data to analyse the factors affecting car ownership. The study found that older individuals were more likely to own cars than younger individuals. Similarly, using a crosssectional data of Dublin city, Nolan (2010) found that age was positively associated with individuals' probability of owning cars. These findings were also evidenced by Rouwendal and Pommer (2004) and Bjorner and Petersen (2004) based on the Dutch and the Danish survey data, respectively. However, Palma and Rochat (2000) found that younger individuals were more likely to own cars than older individuals. This was simply because older individuals tend to face more physical constraints in driving than younger individuals (Matas and Raymond, 2008). In examining the factors associated with the perspective of car ownership in Seoul, Kim et al. (2015) found that older individuals had a higher likelihood of disposing cars than their younger peers. Interestingly, Dargay and Vythoulkas (1999) and Dargay (2001) found an inverse U-shape relationship between age and individuals' likelihood of owing cars, meaning that the likelihood of owing a car was positively associated with age when individuals were young, but was negatively associated when individuals were old.

Education and gender appeared to have significant impacts on car ownership. Raphael and Rice (2002) found that higher educated individuals were more likely to own cars than 
lower educated individuals. However, using data collected in Cambridge, Carse et al. (2013) found that less-educated individuals were more likely to use cars than their well-educated counterparts. Bjorner and Petersen (2004) used a ten-years panel data to examine the determinants of car ownership among households. They found that males were more likely to own a cars compared to females. Raphael and Rice (2002) also found that males had a higher likelihood of owning cars than females. These findings were also shared by Nolan (2010), who claimed that females were less likely to own cars than males. In a recent study, Anowar et al. (2015), using a cross-sectional data of Canada, found that the number of male household members was positively associated with owning multiple cars. Nevertheless, they also observed that the presence of children aged between 5 and 9 years increased the likelihood of owning multiple cars.

The influence of ethnicity on car ownership was not widely considered in previous studies. Drawing on the data of a western country, Rapheal and Rice (2002) found that ethnic minorities, such as Blacks and Hispanics had a lower likelihood of owning cars than ethnic Whites. This was due to the fact that ethnic Whites tend to be employed and had higher incomes than ethnic minorities, and thus were more capable of owning cars (Gautier and Zenou, 2009).

Previous studies consistently found that income played an important role in determining car ownership. Nolan (2010) found that the higherincome individuals were more likely to own cars than the lower-income individuals. Likewise, Thobani (1984), Hensher and Young (1991), Dargay (2001) and Beckman et al. (2008) found that the levels of income were positively associated with individuals' likelihood of owning cars. These findings were also evidence by Clark (2007) based on a cross-sectional data. Palma and Rochat (2000) used a nested logit model to examine the factor affecting individuals' decision to use a cars to work in Geneva. They found that higher-income individuals were more likely to use a cars to work than lower income individuals. Furthermore, Johnson et al. (2010) and Woldeamanuel et al. (2009) found that higher income earners tended to own more cars than lower income earners. The fact was that since a car was a normal good, lower income individuals tend to face more financial constraints in owning cars as compared to higher income individuals (Palma and Rotchat, 2000; Roorda et al., 2000; Johnson et al., 2010). However, Kitamura (2009) found that higher income individuals tended to use public transport more frequently than lower income individuals, while Loo et al. (2015) found an insignificant relationship between income and car ownership in Malaysia.

There were evidences to suggest that accessibility and efficiency of public transport could significantly affect car ownership (Palma and Rotchat, 2000). Based on the data from Dublin, McGoldrick and Caulfield (2015) it can be concluded that rail availability, number of bus-stops and location of residence could predict an individual's behaviour of owing cars. Matas and Raymond (2008) found that individuals who could easily access public transport were less likely to own cars than their counterparts who could not easily access public transport. Interestingly, car park issues also had a significant impact on car ownership. Woldeamanuel et al. (2009) found that individuals who faced difficulty in finding car parks in working or housing areas were less likely to own cars compared to individuals who did not face such difficulty. Furthermore, Carse et al. (2013) found that expensive workplace car parking fees, as well as short commuting distances between the workplace and the home could significantly reduce the likelihood of using cars.

\section{Methods}

\section{Data}

Owing to time, resource and geographical constraints, a non-probabilistic convenient sampling method was used to collect the data. The survey was conducted at several factories located in Bayan Lepas, Penang (Malaysia) 
between February and April 2011. The inclusion criteria were: (a) adults aged 18 years and above; (b) Malaysian citizens; and (c) being employed. The piloted bilingual (Bahasa Malaysia and English) questionnaires were distributed for selfadministration by the respondents. Nevertheless, some explanations were provided by the interviewers upon giving out the questionnaires. During the survey, the respondents were asked to self-report their socio-demographic profiles, as well as their perception of public transport in Malaysia. In addition, the respondents were asked to report whether they faced any parking problems in their residing and working areas. The targeted sample size was 510 respondents, and the overall response rate was $99.61 \%$ (508 respondents).

\section{Variables}

Because of data unavailability, only age, gender, ethnicity, marital status, income, education,

Table 1

Definition of Variables in the Statistical Model personal perspective on public transport, and car park issues were used as the explanatory variables (see Table 1). The respondents' ages were divided into four categories: $18-25$ years, $26-35$ years, $36-45$ years and $\geq 46$ years. This age classification was based on the study by McGoldrick and Caulfield (2015). The respondents' ethnic backgrounds were categorised into three groups: Malay, Chinese and Indian/others. The marital status of the respondents was categorised into two groups: single and non-single (including married, divorced and widowed). Following Cheah's study (2012), the respondents' monthly individual incomes were segmented into four categories: low ( $\leq$ RM 999), lower-middle (RM 1000 - 2999), upper-middle (RM 3000 5999 ) and high ( $\geq$ RM 6000). The respondents' educational backgrounds were grouped into two categories: tertiary educated and non-tertiary educated (i.e. primary and secondary educated).

\begin{tabular}{ll}
\hline Variables & Descriptions \\
\hline Dependent variable & \\
Car owner & Owning a car \\
Yes & Not owning a car \\
No & \\
Explanatory variables & Age is $18-25$ years \\
Age & Age is $26-35$ years \\
Age1825 & Age is $36-45$ years \\
Age2635 & Age is $\geq 46$ years \\
Age3645 & \\
Age46 & Gender is male \\
Gender & Gender is female \\
Male &
\end{tabular}




\begin{tabular}{ll}
\hline Variables & Descriptions \\
\hline Ethnicity & Ethnic group is Malay \\
Malay & Ethnic group is Chinese \\
Chinese & Ethnic group is Indian/others \\
Indian/others & \\
Marital status & Marital status is single \\
Single & Marital status is non-single (i.e. married, divorced, widowed) \\
Non-single & \\
Income & Income is $\leq$ RM 999 \\
Low & Income is RM 1000 - 2999 \\
Lower-middle & Income is RM 3000 - 5999 \\
Upper-middle & Income is $\geq$ RM 6000 \\
High & \\
Tertiary & Education level is tertiary \\
Yes & Education level is lower than tertiary (i.e. primary and secondary) \\
No & Perception of Malaysian public transport is efficient \\
Efficient & \\
Yes & \\
No & Parking issue
\end{tabular}

\section{Statistical analysis}

The dependent variable used in the present study was a binary variable: 1 refered to the respondents who owned casr; 0 refers to the respondents who did not own cars. Such that:

$$
p_{i}= \begin{cases}\operatorname{Pr}\left(y_{i}=1 \mid x_{i}\right) & \text { if } y_{i}=1 \text { is observed } \\ 1-\operatorname{Pr}\left(y_{i}=1 \mid x_{i}\right) & \text { if } y_{i}=0 \text { is observed }\end{cases}
$$

where $p_{i}$ is the probability of observing the value of $y_{i} ; \operatorname{Pr}\left(y_{i}=1 \mid x_{i}\right)$ is the probability of owning a car conditional on $x_{i}$. Hence, the linear probability model (LPM) estimated using the ordinary least square (OLS) can be expressed as:

$$
\operatorname{Pr}\left(y_{i}=1 \mid x_{i}\right)=\beta_{0}+\beta_{1} x_{i 1}+\ldots+\beta_{k} x_{i k}
$$

where $\beta_{0}$ is the probability of owning a car when each $x$ is zero; $\beta_{1}$ measures the change of the probability of owning a car when $x_{1}$ increases by one unit. However, a major drawback of using this linear regression is that the probability can be less than zero or greater than one (Greene, 2007).

Because of the non-linear nature of $\operatorname{Pr}\left(y_{i}=1 \mid x_{i}\right)$, the maximum likelihood estimation (MLE) was used to estimate the probability of owning a car. To obtain the maximum likelihood estimator, the likelihood function was constructed as: 


$$
L(\boldsymbol{\beta})=\prod_{y=1} F\left(\mathbf{x}_{\mathbf{i}} \boldsymbol{\beta}\right) \prod_{y=0}\left[1-F\left(\mathbf{x}_{\mathbf{i}} \boldsymbol{\beta}\right)\right]
$$

where $\mathbf{x}_{i} \beta$ is the matrix form for $\beta_{0}+\beta_{I} x_{i 1}+\ldots+$ $\beta_{k} x_{k i}$. By adding the natural $\log (\ln )$ into equation (3), the log-likelihood function is obtained and can be written as:

$$
\ln L(\boldsymbol{\beta})=\sum_{y=1} F\left(\mathbf{x}_{\mathbf{i}} \boldsymbol{\beta}\right)+\sum_{y=0}\left[1-F\left(\mathbf{x}_{\mathbf{i}} \boldsymbol{\beta}\right)\right]
$$

where $F(\cdot)$ lies between zero and one. Assuming $F(\cdot)$ is the standard logit cumulative distribution function, the present study used the logit model for analysis. The logit cumulative distribution function can be expressed as:

$$
F\left(\mathbf{x}_{\mathbf{i}} \boldsymbol{\beta}\right)=\frac{e^{\mathbf{x}_{\mathrm{i}} \boldsymbol{\beta}}}{1+e^{\mathbf{x}_{\mathbf{i}} \boldsymbol{\beta}}}
$$

Both the Likelihood Ratio (LR) and the HosmerLemeshow (H-L) tests were conducted to test the goodness-of-fit of the regression model. Additionally, the age, income and education variables were tested for multicollinearity using the variance inflation factor (VIF). The level of significance of all the tests was based on $p$-value of less than $10 \%$ (two-sided). Owing to inappropriate and missing information reported by some respondents, only 498 response were used for analysis. Hypothesis tests of difference in proportion were performed to sustain the statistical significance of differences between car owners and non-car owners among the respondents.

\section{Results}

\section{Characteristic of the survey respondents}

The characteristics of the survey respondents is presented in Table 2. Of the total 498 respondents, $113(22.69 \%)$ were car owners, while 385 $(77.31 \%)$ were non-car owners. The majority of the respondents were aged between 26 and 35 years ( $57.43 \%)$, followed by those aged between 18 and 25 years $(22.09 \%)$, between 36 and 45 years $(17.87 \%)$ and 46 years and above $(2.61 \%)$. $83.92 \%$ of the respondents aged between 26 and 35 years were car owners, compared to only $64.55 \%$ of the respondents aged between 18 and 25 years. Of the total sample, $46.59 \%$ were males and $53.41 \%$ were females. $83.46 \%$ of the females owned cars, whereas only $70.26 \%$ of the males were car owners. The ethnic breakdown consisted of $60.84 \%$ Chinese, $27.11 \%$ Malays and $12.05 \%$ Indians and others. Comparison among the ethnic groups, car ownership was more prevalent among the Chinese $(84.16 \%)$ than the Malays $(62.22 \%)$.

Table 2

Descriptive analysis of variables in the statistical model

\begin{tabular}{lcccc}
\hline Variables & $\begin{array}{c}\text { Car owner } \\
\left(\mathrm{n}_{1}=113\right)\end{array}$ & $\begin{array}{c}\text { Non-car owner } \\
\left(\mathrm{n}_{2}=385\right)\end{array}$ & $\begin{array}{c}\text { Total sample } \\
(\mathrm{n}=498)\end{array}$ & $p$-value* \\
\hline Age & & & & \\
Age1825 & 64.55 & 35.45 & 22.09 & $<0.001$ \\
Age2635 & 83.92 & 16.08 & 57.43 & \\
Age3645 & 73.03 & 26.97 & 17.87 & \\
Age46 & 69.23 & 30.77 & 2.61 & \\
\hline
\end{tabular}

(Continued) 


\begin{tabular}{|c|c|c|c|c|}
\hline Variables & $\begin{array}{l}\text { Car owner } \\
\left(\mathrm{n}_{1}=113\right)\end{array}$ & $\begin{array}{l}\text { Non-car owner } \\
\quad\left(\mathrm{n}_{2}=385\right)\end{array}$ & $\begin{array}{l}\text { Total sample } \\
\quad(\mathrm{n}=498)\end{array}$ & $p$-value* \\
\hline \multicolumn{5}{|l|}{ Gender } \\
\hline Male & 70.26 & 29.74 & 46.59 & $<0.001$ \\
\hline Female & 83.46 & 15.54 & 53.41 & \\
\hline \multicolumn{5}{|l|}{ Ethnicity } \\
\hline Malay & 62.22 & 37.78 & 27.11 & $<0.001$ \\
\hline Chinese & 84.16 & 15.84 & 60.84 & \\
\hline Indian/others & 76.67 & 23.33 & 12.05 & \\
\hline \multicolumn{5}{|l|}{ Marital status } \\
\hline Single & 80.32 & 19.68 & 50.00 & 0.109 \\
\hline Non-single & 74.30 & 25.70 & 50.00 & \\
\hline \multicolumn{5}{|l|}{ Income } \\
\hline Low & 30.00 & 70.00 & 4.02 & $<0.001$ \\
\hline Lower-middle & 75.09 & 24.91 & 54.02 & \\
\hline Upper-middle & 83.02 & 16.98 & 31.93 & \\
\hline High & 90.00 & 10.00 & 10.03 & \\
\hline \multicolumn{5}{|l|}{ Tertiary } \\
\hline Yes & 81.96 & 18.04 & 77.91 & $<0.001$ \\
\hline No & 60.91 & 39.09 & 22.09 & \\
\hline \multicolumn{5}{|l|}{ Efficient } \\
\hline Yes & 68.90 & 31.10 & 33.00 & 0.002 \\
\hline No & 81.38 & 18.62 & 67.00 & \\
\hline \multicolumn{5}{|l|}{ Parking issue } \\
\hline Yes & 79.70 & 20.30 & 80.12 & 0.011 \\
\hline No & 67.68 & 32.32 & 19.88 & \\
\hline
\end{tabular}

Note: $* p$-value is based on Pearson $\chi^{2}$ statistic.

Half of the respondents were single (50\%), while the other half were non-single $(50 \%)$. A large proportion of the respondents were in the lower-middle income group (54.02\%), followed by those in the upper-middle $(31.93 \%)$, high $(10.03 \%)$ and low $(4.02 \%)$ income groups. Car ownership is most prevalent among the high income group of respondents $(90.00 \%)$, whereas it is the least prevalent is among the low income group of respondents $(30.00 \%)$. The majority of the respondents have tertiary-education (77.91\%). $81.96 \%$ of the tertiary educated respondents were car owners, compared to only $60.91 \%$ of the non-tertiary educated respondents. Overall, $33.00 \%$ of the respondents had the perception that the public transport in Malaysia was efficient, whereas $67.00 \%$ of the respondents did not have such a perception. Only $68.90 \%$ of 
the respondents who had the perception that the public transport in Malaysia was efficient own cars, whilst $81.38 \%$ of the respondents who do not have such perception are car owners. A large proportion of the respondents faced insufficient car park problems in their housing or working areas (80.12\%). $79.70 \%$ of the respondents who faced insufficient car park problems in their housing or working areas were car owners, compared to $67.68 \%$ of the respondents who did not face such problems.

\section{Factors affecting the odds of owning a car}

Table 3 shows the results of the logit analysis of car ownership. The value of LR $\chi^{2}$ with 13

Table 3

Results of the Logit Analysis of Car Ownership

\begin{tabular}{lccccc}
\hline \multicolumn{1}{c}{ Variables } & Coefficient & $\begin{array}{c}\text { Standard } \\
\text { error }\end{array}$ & Odds ratio & $\begin{array}{c}\text { Confidence } \\
\text { interval }\end{array}$ & $p$-value \\
\hline Constant & 0.427 & 0.794 & - & - & 0.590 \\
Age & - & - & 1.000 & - & - \\
$\quad$ Age1825* & 1.007 & 0.313 & 2.738 & $1.482,5.057$ & 0.001 \\
Age2635 & 0.674 & 0.431 & 1.961 & $0.843,4.563$ & 0.118 \\
Age3645 & 0.523 & 0.762 & 1.687 & $0.379,7.508$ & 0.492 \\
Age46 & & & & & \\
Gender & -0.716 & 0.242 & 0.489 & $0.304,0.785$ & 0.003 \\
Male & - & - & 1.000 & - & - \\
Female* & & & & & - \\
Ethnicity & - & - & 1.000 & - & 0.013 \\
$\quad$ Malay* & 0.679 & 0.273 & 1.973 & $1.155,3.370$ & 0.187 \\
Chinese & 0.521 & 0.395 & 1.684 & $0.777,3.650$ & \\
Indian/others & & & & & - \\
Marital status & 0.348 & 0.293 & 1.417 & $0.799,2.513$ & 0.234 \\
Single & - & - & 1.000 & - & - \\
Non-single* & & & & & - \\
\hline
\end{tabular}

(Continued) degrees of freedom is 76.850 , which has a $p$-value of $<0.001$. Hence, the null hypothesis can be rejected, which indicates that the current regression model fits the data well. The value of Hosmer-Lemeshow (H-L) $\chi^{2}$ with 8 degrees of freedom is 10.380 , which has a $p$-value of 0.239 , thus implying the current regression model is good fit. Furthermore, $80.08 \%$ of the observed values are correctly predicted by the model. The calculated VIFs between the age, income and education variables are all less than 10, suggesting that there is no serious multicollinearity problem in the current regression model (Studenmund, 2006) (see Appendix 1).
Constant

Age 2635

Age3645

Gender

Male

1.000 


\begin{tabular}{|c|c|c|c|c|c|}
\hline Variables & Coefficient & $\begin{array}{l}\text { Standard } \\
\text { error }\end{array}$ & Odds ratio & $\begin{array}{l}\text { Confidence } \\
\text { interval }\end{array}$ & $p$-value \\
\hline \multicolumn{6}{|l|}{ Income } \\
\hline Low & -2.167 & 0.792 & 0.114 & $0.024,0.540$ & 0.006 \\
\hline Lower-middle & -0.757 & 0.560 & 0.469 & $0.156,1.406$ & 0.177 \\
\hline Upper-middle & -0.836 & 0.545 & 0.434 & $0.149,1.262$ & 0.125 \\
\hline High* & - & - & 1.000 & - & - \\
\hline \multicolumn{6}{|l|}{ Tertiary } \\
\hline Yes & 0.537 & 0.311 & 1.710 & $0.930,3.144$ & 0.084 \\
\hline $\mathrm{No}^{*}$ & - & - & 1.000 & - & - \\
\hline \multicolumn{6}{|l|}{ Efficient } \\
\hline Yes & -0.309 & 0.254 & 0.734 & $0.446,1.207$ & 0.223 \\
\hline $\mathrm{No}^{*}$ & - & - & 1.000 & - & - \\
\hline \multicolumn{6}{|l|}{ Parking issue } \\
\hline Yes & 0.530 & 0.275 & 1.699 & $0.990,2.915$ & 0.054 \\
\hline $\mathrm{No}^{*}$ & - & - & 1.000 & - & - \\
\hline $\operatorname{LR} \chi^{2}(13)$ & 76.850 & & & & \\
\hline$p$-value & $<0.001$ & & & & \\
\hline $\mathrm{H}-\mathrm{L} \chi^{2}(8)$ & 10.380 & & & & \\
\hline$p$-value & 0.239 & & & & \\
\hline Correct prediction & $80.08 \%$ & & & & \\
\hline Observations & 498 & & & & \\
\hline
\end{tabular}

Note: * refers to reference/base group. LR refers to likelihood ratio. H-L refers to Hosmer-Lemeshow.

Individuals aged between 26 and 35 years have 2.738 times the odds as individuals aged between 18 and 25 years of owning a car (OR: 2.738; $95 \%$ CI: $1.482,5.057)$. Males have 0.489 times the odds as females of owning a car (OR: 0.489; 95\% CI: $0.304,0.785)$. In terms of ethnicity, Chinese have 1.973 times the odds as Malays of owning a car (OR: 1.973; 95\% CI: 1.155, 3.370). Low income individuals have 0.114 times the odds as high income individuals of owning a car (OR: 0.114; 95\% CI: 0.024, 0.540). Tertiary-educated individuals have 1.710 times the odds as non-tertiary-educated individuals of owning a car (OR: 1.710; 95\% CI: 0.930, 3.144).
Individuals who face problems of insufficient car parking space in their housing or working areas have 1.699 times the odds as individuals who do not face such problems of owning a car (OR: 1.699; 95\% CI: 0.990, 2.915).

\section{Discussion}

The findings of the present study suggest that age, gender, ethnicity, income, education and parking issue are significant in affecting car ownership. Particularly, individuals who are aged between 26 and 35 years, are Chinese 
females, are high income earners, tertiary educated individuals and individuals who face problem of insufficient car parking space problems in their housing or working areas are more likely to own cars compared to others.

Interestingly, the present study finds that middle-aged adults are more likely to own cars than youngsters, whereas there are no significant differences in car ownership between the elderly and the youngsters. This finding is somewhat consistent with those of Dargay and Vythoulkas (1999) and Dargay (2001) that the likelihood of owning a car initially increases with age. It can, thus, be concluded that younger individuals are more probable to use cars, whilst older individuals are more devoted to using public transport. The fact of the matter may be that older individuals face more physical constraints in driving when compared to younger individuals, and consequently have a lower preference for owning cars. Another plausible reason is that older individuals tend to have larger families size, thus, owning cars may be a necessity for them. Because of data limitation, this claim needs to be supported by future studies that include family size as an explanatory variable. The policy implication of this finding is that the government should focus primarily on reducing car ownership among middle-aged adults. The government should make a concerted effort to encourage carpooling among this age group of individuals by emphasising on the benefits of carpooling.

Gender is found to be significantly associated with car ownership as females are more likely to own cars than males. This is in contrast to the findings of Raphael and Rice (2002), Bjorner and Petersen (2004) and Nolan (2010) that males are more likely to own cars than females. Perhaps, this is because sexual harassment is likely to happen in public transport in Malaysia (Pal, 2008). Women may tend to feel unsafe to use public transport, especially during peak hours. Therefore, an effective government intervention strategy should include the need to introduce special buses and taxis for women during peak hours. On top of that, the government should be also consider hiring more women drivers. This is to ensure that women would feel safe and secure to use public transport.

In terms of ethnicity, the finding of the present study suggests that the Chinese have a higher likelihood of owning cars than the Malays, which indirectly indicates the ethnic Chinese play an important role in affecting traffic congestion in Penang. A plausible reason is that the Chinese are the wealthiest ethnic group in Malaysia (China Daily, 2012). Hence, the Chinese tend to be more capable of owning cars when compared to the other ethnic groups. In view of this finding, efforts to reduce car ownership among the Chinese should be made by the government. In particular, the government should uses various Chinese language-based mass media such as newspapers, television programmes and radio channels, as well as religious spokespersons with Chinese ethnic backgrounds to discourage people from owning cars by highlighting the disadvantages of using cars such as environmental pollution and traffic congestion.

Income is found to be statistically significant in affecting car ownership as high income individuals are more likely to own cars than low income individuals, which lends the support to the findings of Thobani (1984), Hensher and Young (1991), Dargay (2001), Beckman et al. (2008) and Nolan (2010). Since cars are normal goods, higher income individuals are more capable of owning then compared to lower income individuals. Therefore, in an effort to reduce car ownership among high income individuals, the government should consider increasing the parking fees in working areas, especially during peak hours. Imposing expensive parking fees may discourage individuals to own cars, thus, reducing the number of cars on the road. Futhermore, the government should also impose a higher tax rate on cars, while subsidising public transportation fees. This is to encourage individuals to opt for using public transport.

The finding of the present study shows that tertiary-educated individuals are more likely to 
own cars than non-tertiary-educated individuals. This supports the findings of Raphael and Rice (2002) that well-educated individuals are more likely to own cars than less-educated individuals. The explanation is that well-educated individuals tend to hold higher position in companies, thus, they are more likely to own cars, as cars are often viewed as status symbols (Golob and Hensher, 1998). As an intervention strategy to reduce car ownership, a successful policy should be targeted primarily at well-educated individuals. For instance, the government could use financial professionals to widely publicise the fact that owning a car will only increase one's financial burden rather than one's status.

Surprisingly, the present study finds that individuals who face problems of insufficient car parking space problems in their housing or working areas are more likely to own cars than individuals who do not face such problems. Thus is in contrast to the finding of Woldeamanuel et al. (2009). The contributing factor for this outcome needs to be further investigated by future qualitative studies focusing on the relationship between car park issues and the availability of public transport.

\section{Conclusion}

In light of the serious traffic congestion problem in Penang (Malaysia), the present study set out to investigate the factors affecting car ownership among working adults. Using a logit model, the present study found that age, gender, ethnicity, income, education and parking issue are significant in affecting car ownership. However, owing to time, budget and geographical constraints, the present study has an inherent limitation in that the surveyed area was limited to individuals working in Bayan Lepas and the sample was not collected based on a probability sampling approach. Ideally, the respondents travelling to and from work from all over the Penang Island, as well as the mainland should be taken into consideration and canvassed using random sampling in order to obtain a more representative sample.

\section{References}

Beckman, J. D. \& Goulias, G. K. (2008) .Immigration, residential location, car ownership and commuting behavior: A multivariate latent class analysis from California. Transportation, 35(5), 655671.

Bjorner, T. B., \& Leth-Peterson, S. (2004). Dynamic models of car ownership at the household level. Amternes $O g$ Kommunernes Forskningsinstitut. Working paper.

Cheah, Y. K. (2012). An exploratory study on self-rated health status: The case of Penang, Malaysia. Malaysian Journal of Economic Studies, 49(2), 141-155.

China Daily (2012) .80\% of 40 richest Malaysians are ethnic Chinese. China Daily, [online] 3 February. Available at: http://www. chinadaily.com.cn/business/2012-02/03/ content_15781890.htm [Accessed on 28 September 2013].

Clark, S. D. (2007). Estimating local car ownership models. Journal of Transport Geography, 15(3), 184-197.

Dargay, J. M. (2001). The effect of income on car ownership: Evidence of asymmetry. Transportation Research Part A: Policy and Practice, 35(9), 807-821.

Dargay, J. M., \& Vythoulkas, P. C. (1999) .Estimation of a dynamic car ownership model: A pseudo-panel approach. Journal of Transport Economics and Policy, 33(3), 287-302.

Frank, R. H. (2008) .Microeconomics and behavior (7th ed). ,New York: McGrawHill.

Gautier, P. A, \& Zenou, Y. (2009). Car ownership and the labor market of ethnic minorities. Journal of Urban Economics, 67(3), 392-403.

Golob, T. F., \& Hensher, D. A. (1998). Greenhouse gas emissions and Australian commuters' attitudes and behaviour concerning abatement policies and personal involvement. Transportation Research Part D: Transport and Environment, 3(1), 1-18. 
Greene, W. H. (2007). Econometric analysis, (6th ed). New York: Prentice Hall.

Hensher, D. A., \& Young, J. L. (1991). Demand forecasts and demand elasticities for Australian transport fuel. Bureau of Transport and Communications Economics. Occasional paper No. 103.

Johnson, V., Currier, G., \& Stanley, J. (2010) .Measures of disadvantage: Is car ownership a good indicator? Social Indicators Research, 97(3), 439-450.

Kitamura, R. (2009) A dynamic model system of household car ownership trip generation, and modal split: Model development and simulation. Transportation, 36(6), 711732.

Matas, A., \& Raymond, J. L. (2008). Changes in the structure of car ownership in Spain. Transportation Research Part A: Policy and Practice, 42(1), 187-202.

Nolan, A. (2010). A dynamic analysis of household car ownership. Transportation Research Part A: Policy and Practice, 44(6), 446-455.

Pal, V. (2008) .The trauma of sexual harassment on commuter trains. The Star, [online] 16 January. Available at: http://www. thestar.com.my/Story.aspx file $=\% 2 \mathrm{~F}$ $2008 \% 2$ F $1 \% 2$ F $16 \% 2$ Fcentral\% 2F 19 999361\&sec $=$ central [Accessed on 28 September 2013].

Palma, A., \& Rochat, D. (2000). Mode choices for trips to work in Geneva: An empirical analysis. Journal of Transport Geography, 8(1), 43-51.

Raphael, S., \& Rice, L. (2002). Car ownership, employment and earnings. Journal of Urban Economics, 52(1), 109-130.
Roorda, M. J., Mohammadian, A., \& Miller, E. J. (2000) .Toronto area car ownership study: A retrospective interview and its applications. Transportation Research Record, 1719, 69-76.

Rouwendal, J., \& Pommer, J. (2004) .An indirect utility model of multiple car ownership and use. Tinbergen Institute Discussion Paper. Working paper No. TI 2004085/3.

Studenmund, A. H. (2006). Using econometrics: A practical guide (5th ed). New York: Pearson.

The Star. (2011). Number of vehicles registered on the rise. The Star, [online] 26 February. Available at: http://www.thestar.com. my/Story.aspx ?file $=\% 2 \mathrm{~F} 2011 \% 2 \mathrm{~F} 2 \% 2 \mathrm{~F}$ $26 \% 2$ Fnation $\% 2 \mathrm{~F} 8146407 \& \mathrm{sec}=$ nation [Accessed on 28 September 2013].

Thobani, M. (1984). A nested logit model of travel mode to work and auto ownership. Journal of Urban Economics, 15(3), 287301.

Woldeamanuel, M. G., Cyganski, R., Schulz, A., \& Justen, A. (2009). Variation of households' car ownership across time: Application of a panel data model. Transportation, 36(4), 371-387. 
Appendix 1: Correlation between age, income and education

\begin{tabular}{lc}
\hline Variables & VIF \\
\hline Age & - \\
Age1825 & 1.75 \\
Age2635 & 1.92 \\
Age3645 & 1.20 \\
Age46 & \\
Income & 1.68 \\
Low & 3.60 \\
Lower-middle & 3.07 \\
Upper-middle & - \\
High & \\
Tertiary & \\
Yes & \\
No & 1.37 \\
\hline Note: VIF refers to variance inflation factor. & - \\
\hline
\end{tabular}

